\title{
Reliability of Point-of-Care Testing of INR in Acute Stroke
}

\author{
Theresa L. Green, Adnan Mansoor, Nancy Newcommon, Caroline Stephenson, \\ Eileen Stewart, Michael D. Hill
}

\begin{abstract}
Background: In the emergency department, portable point-of-care testing (POCT) coagulation devices may facilitate stroke patient care by providing rapid International Normalized Ratio (INR) measurement. The objective of this study was to evaluate the reliability, validity, and impact on clinical decision-making of a POCT device for INR testing in the setting of acute ischemic stroke (AIS). Methods: A total of 150 patients (50 healthy volunteers, 51 anticoagulated patients, 49 AIS patients) were assessed in a tertiary care facility. The INR's were measured using the Roche Coaguchek S and the standard laboratory technique. Results: The interclass correlation coefficient and $95 \%$ confidence interval between overall POCT device and standard laboratory value INRs was high (0.932 $(0.69-0.78)$. In the AIS group alone, the correlation coefficient and 95\% CI was also high $0.937(0.59-0.74)$ and diagnostic accuracy of the POCT device was $94 \%$. Conclusions: When used by a trained health professional in the emergency department to assess INR in acute ischemic stroke patients, the CoaguChek $\mathrm{S}$ is reliable and provides rapid results. However, as concordance with laboratory INR values decreases with higher INR values, it is recommended that with CoaguChek S INRs in the $>1.5$ range, a standard laboratory measurement be used to confirm the results.
\end{abstract}

RÉSUMÉ: Fiabilité de l'INR effectué au point d'intervention dans l'accident vasculaire cérébral aigu. Contexte : À la salle d'urgence, les appareils portatifs pour analyse de l'INR au point d'intervention (API) peuvent faciliter les soins prodigués aux patients atteints d'accidents vasculaires cérébraux (AVC). Le but de cette étude était d'évaluer la fiabilité, la validité et l'impact sur la décision clinique de l'INR effectué au moyen d'un appareil d'API dans le contexte de l'AVC aigu. Méthodes : Cent cinquante patients, soit 50 volontaires sains, 51 patients anticoagulés et 49 patients atteints d'un AVC aigu, ont été évalués dans un centre de soins tertiaires. Le Roche Coaguchek S et la technique standard de laboratoire ont été utilisés pour mesurer l'INR. Résultats : Globalement, le coefficient de corrélation interclasse et l'intervalle de confiance à $95 \%$ entre la valeur de l'INR mesurée par l'appareil d'API et la valeur mesurée par la technique standard de laboratoire était élevée (CC0,932; IC95\% 0,69 à 0,78). Dans le groupe de patients présentant un d'AVC aigu, le coefficient de corrélation était également élevé $(0,937$; IC95\% 0,59 à 0,74$)$ et la précision diagnostique de l'appareil d'API était 94\%. Conclusions : Quand le CoaguChek S est utilisé à la salle d'urgence par un professionnel de la santé entraîné pour mesurer l'INR chez des patients atteints d'un AVC ischémique aigu, l'appareil est fiable et rapide. Cependant, étant donné que la concordance entre les valeurs d'INR obtenues au moyen de l'appareil et par la technique standard diminue lorsque les valeurs d'INR sont plus élevées, il est recommandé d'obtenir confirmation des résultats par la méthode standard quand la valeur obtenue par CoaguChek $\mathrm{S}$ est $>1,5$.

Can. J. Neurol. Sci. 2008; 35: 348-351

Advances in the treatment of acute ischemic stroke (AIS) offers patients hope in reducing the potentially devastating effects of stroke. The major change in stroke care in the past decade has been the use of thrombolytic agents. Only two thrombolytics, intravenous recombinant tissue plasminogen activator (rt-PA) and intraarterial pro-urokinase, have been proven effective in randomized double-blinded placebo trials. ${ }^{1,2}$

For clinicians, one major barrier to early treatment is the delay in accessing the prothrombin time, particularly evident when patients present with aphasia or are currently receiving warfarin therapy. Use of warfarin is increasing with the aging population due to the increase of atrial fibrillation. Many patients on warfarin therapy for atrial fibrillation who present to hospital with acute ischemic stroke present with sub-therapeutic INR levels. An INR $<2.0$ is associated with an increase in the frequency and the severity of ischemic stroke. ${ }^{3}$ Additionally, current wait times of up to an hour for an INR result from the hospital laboratory may delay or remove the option of

From the Calgary Stroke Program, Department of Clinical Neurosciences, University of Calgary, and Calgary Laboratory Services, Calgary, AB, Canada.

Received November 19, 2007. Final Revisions Submitted February 16, 2008. Reprint requests to: Theresa L. Green, Calgary Stroke Program, Department of Clinical Neurosciences, University of Calgary, Foothills Hospital, Rm C1101A, 1403-29th Street NW, Calgary, Alberta, T2N 2T9, Canada. 
thrombolytic treatment for these acute stroke patients. The purpose of this study therefore, was to evaluate the reliability and potential benefits of point-of-care testing (POCT) of INR in the acute stroke patient population.

Point-of care testing, if shown to be reliable in this population, has the potential to decrease morbidity and mortality by improving the door to needle time for thrombolytic treatment. Point-of-care testing uses whole capillary blood to measure prothrombin time and INR with results typically obtained in less than five minutes. ${ }^{4}$ These portable machines were primarily developed for patient self-testing and rural community testing, and have also been used during anaesthesia and dental procedures. $^{5-9}$ In the majority of published studies, the POCT systems are judged almost as reliable as the INR results from community hospital labs, with INR $<3$ or 4 (Mean Relative Deviation < 10\%). ${ }^{10,11}$ Results obtained using the Roche CoaguChek S System, the portable machine used in this protocol, has shown a significant correlation with laboratory results if the INR is $<3$ or $4 .{ }^{12,13}$ Researchers also revealed a mean difference of 0.09 INR units with INR $<2$ and 0.19 units with INR $<3$ in a study utilizing the CoaguChek $\mathrm{S}$ predecessor, the Roche CoaguChek. ${ }^{14}$ The limitations of the system seem totally acceptable in acute stroke therapy where the main values of interest lie under INR of 2 and the current Canadian standard of care for acute ischemic stroke contraindicates thrombolysis in patients with an INR of $>1.4$ (note: current US guidelines suggest an INR of 1.7). ${ }^{15,16}$

The primary aim of this study was to confirm the acceptable reliability of the Roche Coaguchek S System in discriminating between an INR of less than or greater than 1.5, (value arbitrarily chosen to accommodate current US and Canadian standards for tPA administration) as compared to laboratory values, in nonanticoagulated patients and anticoagulated patients. Good reliability was defined as a difference in the INR of less than 0.2 between laboratory and device values. A secondary aim was to evaluate the potential use of INR point-of-care testing in acute stroke patients in decreasing the time to thrombolytic treatment.

\section{METHODS}

A two-phased, prospective cohort study was conducted at the Foothills Medical Centre in Calgary, Alberta. A convenience sample of 150 participants was entered into the study. Phase one, in which the accuracy of the Coaguchek S POCT device as compared to laboratory-based INR values was assessed, included one group of 51 healthy volunteers and a second group of 48 anticoagulated inpatients. Phase two of the study was to assess the reliability and utility of the POCT device in an acute stroke setting and included 51 consecutive AIS patients assessed in the emergency department. A single POCT device was used throughout the study, manufacturer's and laboratory services quality assurance procedures were scrupulously followed, laboratory testing followed within ten minutes of the POCT finger stick, and study nurses obtaining the POCT sample were trained in the use of the device.

Ethical approval for the study was received from the Calgary Conjoint Ethics Review Board and informed consent was obtained from all Phase I participants prior to any data or sample collection. Waiver of consent, based on the Canadian Tri-council Guidelines on Human Subjects Research, was obtained for Phase II participants.
Healthy volunteers included nursing staff, students, trainees, and medical personnel in the Department of Clinical Neurosciences stroke program. Patient participants in phase one were approached on the stroke unit or the anticoagulation clinic at the Foothills Medical Centre. Venous and POCT specimens were collected within minutes of each other. Older patients on warfarin for cardiac conditions, post-MI patients on warfarin, patients' anti-coagulated for venous thromboembolic disease, and those with liver disease were tested. The accuracy of the POCT INR device, defined as the extent of comparability of the POCT results with standard laboratory results, and the difference of time to results were compared. Basic demographic information from phase one participants, specifically sex, age, disease and warfarin use, were collected.

The reliability and utility of the CoaguChek S System in acute stroke situations was examined in phase two of the study. Portable INR POCT and standard laboratory values were evaluated in 51 consecutive AIS patients seen by the stroke team in the emergency department. One patient in phase two was excluded from the final analysis as laboratory INR values were unavailable. Participants recruited for this phase included AIS patients presenting less than six hours from symptom onset, with a POCT INR specimen obtained via finger poke collected within ten minutes of the venous blood specimen draw. Demographic information included sex, age, stroke type, use of anticoagulants, and time from symptom onset.

\section{Statistical Methods}

Data were analyzed using the Statistical Package for the Social Sciences (SPSS) (Version 15, SPSS Corporation, Chicago, IL). Data are shown using standard descriptive statistics. Continuous variables were compared using the t-test for normally distributed data. Categorical variables were compared using chi-square and Fisher's exact test, as appropriate. The INR results were dichotomized to $\leq 1.5$ or $>$ 1.5. Linear regression was used to analyse the relationship between POCT and laboratory INR results.

\section{RESULTS}

Demographic data of the entire sample are described in the Table. The overall sample was predominantly Caucasian (82.4\%) with a median age of 72.0 years (range of $22-94$ years). There was a statistically significant difference between the three groups in terms of age. The volunteer group was significantly younger than both patient groups $(\chi 2=76.52, \mathrm{p}<0.0001)$. The mean time to POCT INR results was $<1$ minute for all three cohorts. There were significant differences in the mean time to laboratory INR results between the three groups $\left(\chi^{2} 78.46, p=0.000\right)$. The mean times to obtain laboratory INR results were 129.10 (SD 40.31) minutes for the healthy volunteer group, 65.95 (SD 49.76) minutes for the anticoagulation cohort, and 55.82 minutes (SD 20.84) for the acute ischemic stroke cohort.

Pearson product-moment correlations were conducted to compare POCT and laboratory INR values for each group and significant correlations were found: volunteers $(\mathrm{r}=0.371, \mathrm{p}=$ 0.007); anticoagulated patients $(\mathrm{r}=0.868, \mathrm{p}=0.000)$; AIS patients $(\mathrm{r}=0.873 \cdot \mathrm{p}=0.000)$. The interclass correlation coefficient $(95 \%$ $\mathrm{CI}$ ) between the overall sample POCT Coaguchek $\mathrm{S}$ and laboratory values was equal to $0.932(.69-.78)$. 
Paired t-tests were conducted to compare differences between POCT and laboratory INR values in each study group. No significant differences were found in the volunteer group [ $\mathrm{t}=0.324$ (49), $\mathrm{p}=0.748]$, anticoagulated patient group $[\mathrm{t}=0.477$ (50), $\mathrm{p}=0.636]$, or the acute ischemic stroke group [ $\mathrm{t}=1.872$ (47), $\mathrm{p}=0.067]$. Linear regression analysis of overall study data revealed that the POCT device tended to overestimate the true INR on average by about $1 / 3^{\text {rd }}$ of an INR unit $($ LAB INR $=0.733$ * POCT INR + 0.347). Linear regression analysis of the AIS group alone revealed the POCT device also overestimated the true INR by about $1 / 3^{\text {rd }}$ of an INR unit (LAB INR $=0.666 *$ POCT INR +0.359). Clinically, this overestimation of the POCT INR results as compared to laboratory test values was felt to be nonsignificant for INR values below 2.0 and for patients with a true INR $<1.5$, POCT values were consistent (Figure). In the acute ischemic stroke group $(n=50)$, the proportion of patients with a true positive test (LAB and device INR $>1.5)$ was $100 \%(\mathrm{n}=3)$; a true negative test (LAB and device INR $\leq 1.4$ ) was $98 \%$ $(\mathrm{n}=46)$; a false positive test (LAB INR $\leq 1.4$ but device INR $>$ 1.4) was $2 \%(\mathrm{n}=1)$; and a false negative test (LAB INR $\geq 1.4$ and device INR < 1.4 ) was $0 \%$.

Table: Demographics

\begin{tabular}{|c|c|c|c|}
\hline & $\begin{array}{c}\text { Volunteers } \\
(\mathrm{n}=51)\end{array}$ & $\begin{array}{l}\text { Anticoagulated } \\
\text { Patients } \\
(\mathrm{n}=48)\end{array}$ & $\begin{array}{c}\text { AIS Patients } \\
(\mathrm{n}=50)\end{array}$ \\
\hline Age $\bar{X}(\mathrm{SD})$ & $\begin{array}{l}42.0(10.59) \\
\text { (range 22- } \\
66)\end{array}$ & $\begin{array}{c}74.8(14.55) \\
\text { (range 28-94) }\end{array}$ & $\begin{array}{c}75.6(14.30) \\
\text { (range 28-94) }\end{array}$ \\
\hline Female $\%(n)$ & $68.6(35)$ & $46.9(23)$ & $52.0(26)$ \\
\hline Anticoagulation \% (n) & $\begin{array}{c}- \\
- \\
-\end{array}$ & $\begin{array}{c}100(48) \\
- \\
-\end{array}$ & $\begin{array}{c}10(5) \\
78(39) \\
12(6)\end{array}$ \\
\hline INR $\bar{X}(\mathrm{SD})$ & $\begin{array}{l}.982(.059) \\
.988(.091)\end{array}$ & $\begin{array}{c}2.42(.934) \\
2.61(1.348)\end{array}$ & $\begin{array}{l}1.057(.216) \\
1.051(.389)\end{array}$ \\
\hline $\mathrm{PT} \quad \bar{X}(\mathrm{SD})$ & $\begin{array}{l}11.61(.567) \\
12.19(.511)\end{array}$ & $\begin{array}{c}28.11(10.622) \\
19.86(4.989)\end{array}$ & $\begin{array}{l}11.79(2.457) \\
12.55(1.535)\end{array}$ \\
\hline $\begin{array}{l}\text { Time to laboratory results in minutes } \bar{X} \\
\text { (SD) }\end{array}$ & $\begin{array}{c}129.1 \\
(40.31)\end{array}$ & $65.95(49.76)$ & $55.82(20.84)$ \\
\hline $\begin{aligned} \text { Time to POCT results in minutes } \% & \text { (n) } \\
& <1 \mathrm{~min} \\
& <2 \mathrm{~min}\end{aligned}$ & $\begin{array}{c}84.3(43) \\
15.7(8)\end{array}$ & $\begin{array}{l}78.7(38) \\
21.3(10)\end{array}$ & $\begin{array}{c}82.0(41) \\
18.0(9)\end{array}$ \\
\hline Last seen normal \% (n) & $\mathrm{n} / \mathrm{a}$ & $\mathrm{n} / \mathrm{a}$ & $\begin{array}{c}23.4(11) \\
27.7(13) \\
29.8(14) \\
6.4(3) \\
12.8(6)\end{array}$ \\
\hline $\begin{array}{r}\text { Anticoagulation status \% (n) } \\
\text { INR known } \\
\text { recent INR unknown }\end{array}$ & $\mathrm{n} / \mathrm{a}$ & $\mathrm{n} / \mathrm{a}$ & $\begin{array}{l}34(17) \\
66(33)\end{array}$ \\
\hline 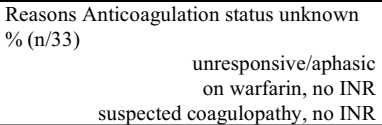 & & & $\begin{array}{l}61.8(21) \\
5.9(2) \\
2.9(1)\end{array}$ \\
\hline
\end{tabular}

$\mathrm{INR}=$ international normalized ratio; $\mathrm{POCT}=$ point-of-care testing device

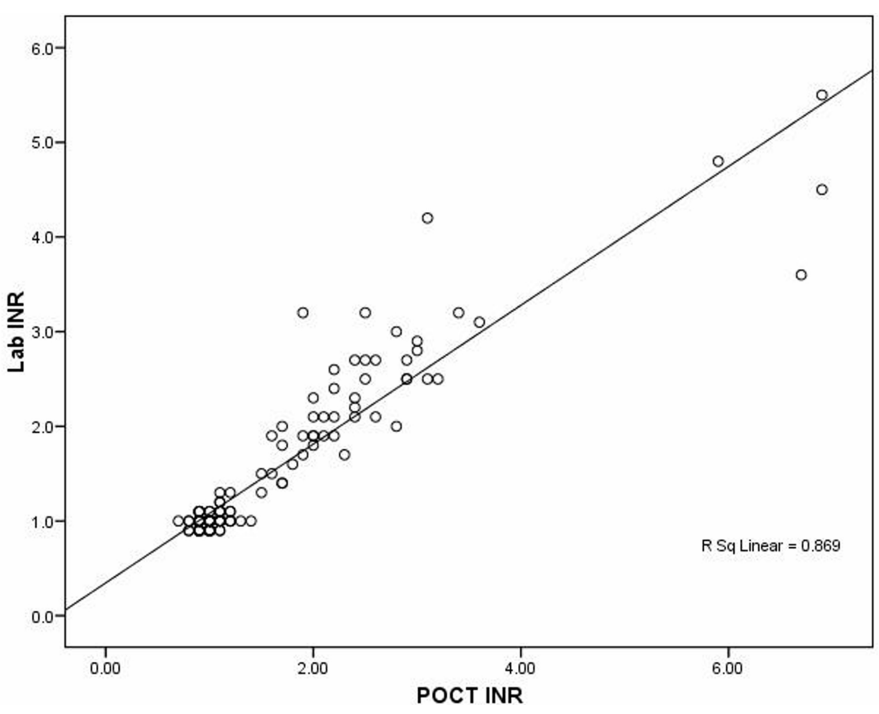

Figure: Scatterplot of bivariate overall POCT and laboratory data

In assessing the utility of the POCT device in the setting of AIS, a total of 24 of 50 patients arrived in the emergency department less than three hours from symptom onset. Twelve of these 24 patients $(24.0 \%$ ) arrived in less than 90 minutes, while 14 patients $(28.0 \%)$ arrived under three hours from symptom onset. The mean time to laboratory INR results in the emergency department was 55 minutes while POCT results were available in one-two minutes. Thus for nearly half of the patients in the AIS group, the delay in obtaining the INR result from the laboratory factored into the clinician's ability to determine thrombolytic treatment options and in $6: 14$ cases $(42.8 \%)$, the decision to initiate thrombolytic therapy was delayed. In terms of ease of use of the POCT device, there were no cases in which INR could not be measured.

\section{Conclusions}

In our study, among patients with a true INR $<1.5$, the POCT device results were consistent with laboratory INR values. This demonstrates that when used by trained health care professionals in the emergency department, the Roche Coaguchek S produces reliable results comparable to standard laboratory values. These results are similar to previously reported results on the validity of other portable coagulation devices in other settings., ${ }^{4,5,17}$ In concordance with results obtained by Lizotte et al $(2003),{ }^{13}$ it is evident that validity of results decreases as INR values increase, thus confirmation of high POCT INR values should be obtained using standard laboratory techniques. Similarly, Gosselin et al (2000) compared INR values obtained from nine different types of POCT monitors with laboratory INRs and also reported that although accurate results were obtained by each device (values within 0.4 units of each other), POCT and laboratory values were less correlated in higher INR ranges. ${ }^{18} \mathrm{~A}$ review by Katz and 
Marques (2004) also identified a tendency for POCT devices to lose comparability with laboratory INR values at higher levels. ${ }^{19}$ As the current Canadian standard of care precludes the use of thrombolytics in the setting of INR values $>1.4$, this does not necessitate a change in practice. The present study therefore, adds to the body of literature supporting the use of POCT devices and in particular supports use of these devices as standard practice in the setting of acute ischemic stroke care. It is important to note however, that the results of this study are limited to the use of a POCT device by trained health care professionals in the acute care setting. The study also tested one brand of POCT device and similar results may not be reproducible with other devices.

In the setting of acute ischemic stroke, the decision to initiate intravenous thrombolytic therapy will often rest on the INR results; coupled with delays in presentation to the acute care setting, delays in obtaining an INR result may push the patient over the three hour window. In our study the mean time to laboratory INR results in emergency department was 55 minutes. Given that the majority of AIS patients arrive in the emergency department $>2$ hours after symptom onset and must also undergo diagnostic CT imaging to rule out hemorrhagic stroke, time to initiate thrombolytic therapy becomes very limited. The use of the POCT device decreased the time required to obtain a reliable INR, permitting an earlier treatment with thrombolytic therapy and possibly a better outcome for the patients. Thus the potential uses and benefits of POCT for AIS in acute, emergency settings would be a very viable option to laboratory INR testing.

\section{ACKNOWLEDGMents ANd Funding}

The authors thank former stroke program staff nurse Linda Anderson-Armitage RN BN, for her assistance with conducting the POCT testing in the early stages of this study. We would like to thank Calgary Laboratory Services staff, in particular Bev Madden and Donna Duce, for their assistance with the conduct of this study. This study was supported by a grant from Calgary Laboratory Services Research department.

\section{CONFLICTS OF INTEREST}

Dr. Hill has received honouraria from Hoffman-La Roche Canada for educational symposia. Hoffman-La Roche has provided Activase (tPA) as a gift in kind for studies done by the Calgary Stroke Program.

\section{REFERENCES}

1. The National Institute of Neurological Disorders and Stroke rt-PA Stroke Study Group. Tissue plasminogen activator for acute ischemic stroke. N Eng J Med. 1995;333:1581-7.

2. Furlan A, Higadasha R, Wechsler L, Gent M, Rowley H, Kase C, et al. Intra-arterial prourokinase for acute ischemic stroke. The PROACT II study: a randomized controlled trial. Prolyse in acute cerebral thromboembolism. JAMA. 1999;282:2003-11.

3. Hylek E, Go A, Chang Y, Jensvold N, Henault L, Selby J, et al. Effect of intensity of oral anticoagulation on stroke severity and mortality in atrial fibrillation. N Eng J Med. 2003;349:1019-26.

4. van den Besselaar AM. Accuracy, precision, and quality control for point-of-care testing of oral anticoagulation. J Thromb Thrombolysis. 2001;12:35-40.

5. Cachia P, McGregor E, Adlakha S, Davey P, Goudie B. Accuracy and precision of the TAS analyser for near-patient INR testing by non-pathology staff in the community. J Clin Pathol. 1998; 51:68-72.
6. Hirsch J, Wendt T, Kuhly P, Schaffartzik W. Point-of-care testing apparatus. Measurement of coagulation. Anaesthesia. 2001;56: 760-3.

7. Oral Anticoagulation Monitoring Study Group. Prothrombin measurement using a patient self-testing system. Oral Anticoagulation Monitoring Study Group. Am J Clin Pathol. 2001;115:280-7.

8. Oral Anticoagulation Monitoring Study Group. Point-of-care prothrombin time measurement for professional and patient selftesting use. A multicenter clinical experience. Am J Clin Pathol. 2001;115(2):288-96.

9. Plaza-Costa A, Garcia-Romero P, Poveda-Roda R, Bagan JV, Silvestre-Donat FJ, Cervero JA. A comparative study between INR and the determination of prothrombin time with the Coaguchek(r) portable coagulometer in the dental treatment of anticoagulated patients. Medicina Oral. 2002;7(2):130-5.

10. Murray E, Greaves M. INR and point of care testing. BMJ. 2003;327:5-6.

11. Sciach C, Campbell B, Poller L, Keown M, Chauhan N. Reliability of point-of-care prothombin time testing in a community clinic: a randomized crossover comparison with hospital laboratory testing. Br J Haematol. 2002;119:370-5.

12. Havrda D, Hawk T, Marvin C. Accuracy and precision of the Coaguchek $S$ versus laboratory INRs in a clinic. Ann Pharmacother. 2006;36:769-75.

13. Lizotte A, Quessy I, Vanier MC, Martineau J, Caron S, Darveau M, et al. Reliability, validity and ease of use of a portable point-ofcare coagulation device in a pharmacist-managed anticoagulation clinic. J Thromb Thrombolysis. 2002;14(3):247-54.

14. Douketis J, Lane E, Milne J, Ginsberg J. Accuracy of a portable international normalized ratio monitor in outpatients receiving long-term oral anticoagulant therapy: comparison with a laboratory reference standard using clinically relevant criteria for agreement. Thromb Res. 1998;92:11-17.

15. Cote R, Roussin A, Sharma M, Oliva V, deVeber G, Teal P. Thrombolysis for Acute Ischemic Stroke. 2007 Available from: http://www.tigc.org/eguidelines/thrombolysisachutestroke07.htm

16. Adams HP, Brott TG, Furlan AJ, Gomez CR, Grotta J, Helgason $\mathrm{CM}$, et al. Guidelines for thrombolytic therapy for acute stroke: a supplement to the guidelines for the management of patients with acute ischemic stroke: a statement for healthcare professionals from a special writing group of the stroke council, American Heart Association. Circulation. 1996 Sep1;94(5): 1167-74.

17. Sanders K, Lewis S, Cooper S, England J. An evaluation of the Nycomed Thrombutrate system. London: NHS Procurement Directorate; 1989.

18. Gosselin R, Owings $\mathrm{J}$, White $\mathrm{R}$, Hutchinson $\mathrm{R}$, Branch $\mathrm{J}$, Mahackian K, et al. A comparison of point-of-care instruments designed for monitoring oral anticoagulation with standard laboratory methods. Thromb Haemost. 2000;89: 698-703.

19. Katz B, Marques M. Point-of-care testing in oral anticoagulation: what is the point? MLO Med Lab Obs. 2004;31-4. 